\title{
SMARTPHONE USE UNDERMINES ENJOYMENT OF FACE-TO-FACE SOCIAL INTERACTIONS
}

by

Ryan Dwyer

B.A., The University of Nevada Reno, 2012

A THESIS SUBMITTED IN PARTIAL FULFILLMENT OF THE REQUIREMENTS FOR THE DEGREE OF

MASTER OF ARTS

in

THE FACULTY OF GRADUATE AND POSTDOCTORAL STUDIES

(Psychology)

THE UNIVERSITY OF BRITISH COLUMBIA

(Vancouver)

June 2017

CC Ryan Dwyer, 2017 


\section{Abstract}

Decades of research on human happiness points to one central conclusion: Engaging in positive social interactions is critical for well-being. The current smartphone revolution, however, may be altering how and when we derive these benefits. Using a field experiment and experience sampling, we found the first evidence that phone use may undermine the enjoyment people derive from real world social interactions. In Study 1, we recruited over 300 community members and students to share a meal at a restaurant with friends or family. Participants were randomly assigned to keep their phones on the table or to put their phones away during the meal. When phones were present (vs. absent), participants felt more distracted, which reduced how much they enjoyed spending time with their friends/family. We found consistent results using experience sampling in Study 2; during in-person interactions, participants felt more distracted and reported lower enjoyment if they used their phones than if they did not. This research suggests that despite their ability to connect us to others across the globe, phones may undermine the benefits we derive from interacting with those across the table. 


\section{Lay Summary}

Positive social interactions are critical for well-being; however, the current technological revolution is altering when and how we interact with others. Across two studies, we found evidence that phone use may undermine the enjoyment people derive from real world social interactions. In Study 1, we manipulated whether participants used their phones during a meal with their friends/family. When phones were present (vs. absent), participants felt more distracted, which reduced how much they enjoyed spending time with their friends/family. We found consistent results in Study 2 by asking participants to report what they were doing and feeling throughout the day. During in-person interactions, participants felt more distracted and reported lower enjoyment if they used their phones than if they did not. This research suggests that phones may undermine the benefits we derive from our real-world social interactions. 


\section{Preface}

This project was developed in collaboration with my advisor Dr. Elizabeth Dunn, and our collaborator, Dr. Kostadin Kushlev. I designed the studies in collaboration with Dr. Dunn and Dr. Kushlev. I was primarily responsible for collecting, analyzing, and interpreting the data of Study 1. Dr. Kushlev collected and analyzed the data for Study 2. A version of this thesis was submitted for publication, and is under review. I wrote the majority of the manuscript, under the supervision of Dr. Dunn. Dr. Kushlev originally drafted the results section of Study 2. The UBC Behavioral Research Ethics Board approved this research, under certification number H1100585. 


\section{Table of Contents}

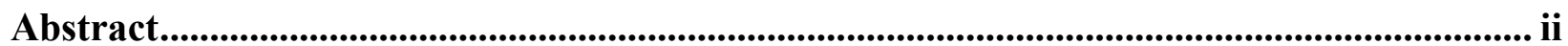

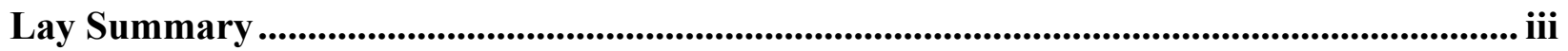

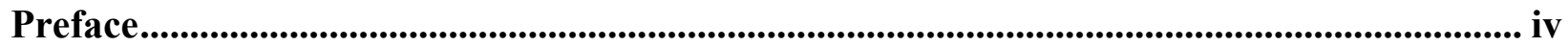

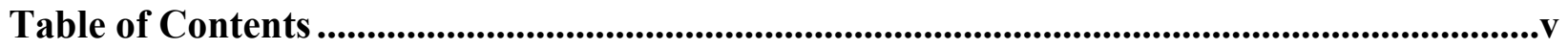

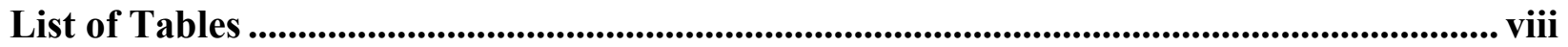

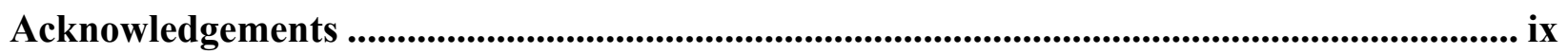

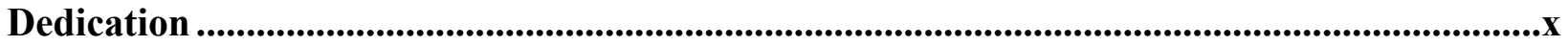

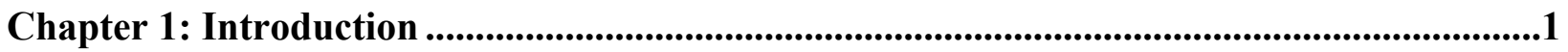

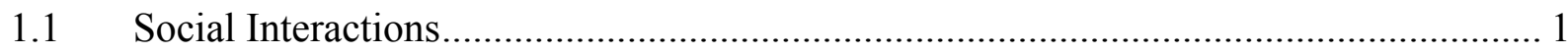

1.2 Potential Psychological Costs of Phone Use ........................................................ 1

1.3 Potential Psychological Benefits of Phone Use ................................................. 2

$1.4 \quad$ Past Research and Current Approach …............................................................. 2

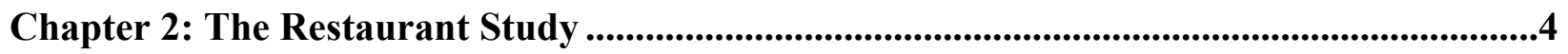

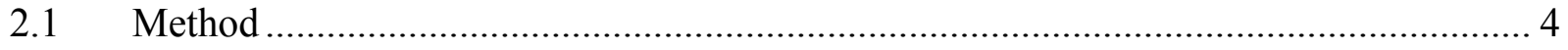

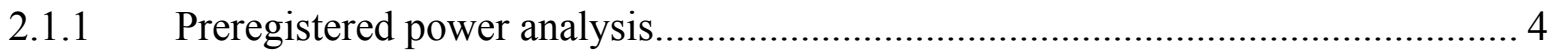

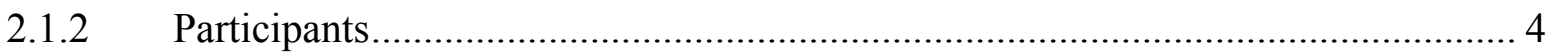

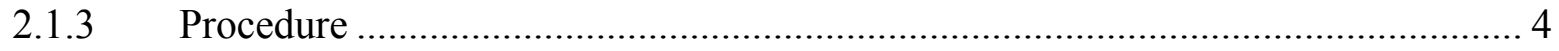

2.1.4 Preregistered Hypotheses..................................................................... 5

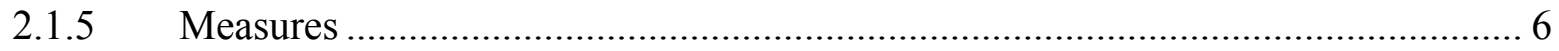

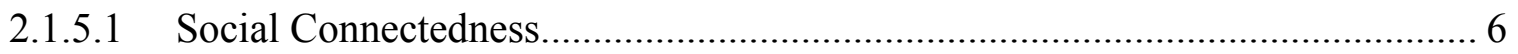

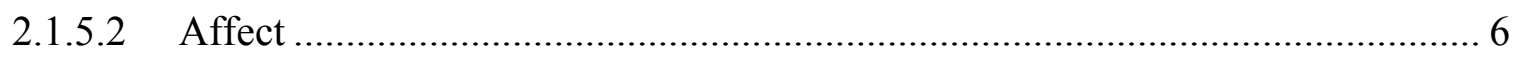




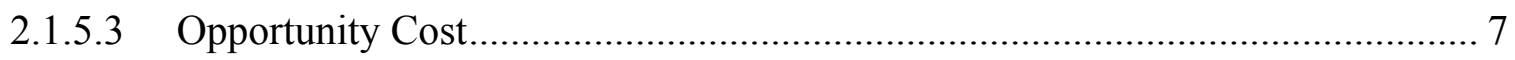

2.1.5.4 Interest and Enjoyment ........................................................................ 7

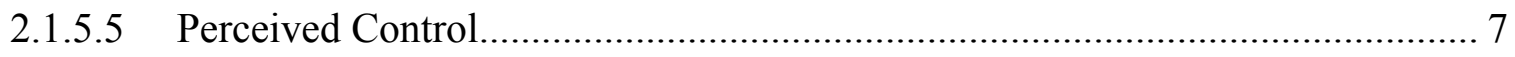

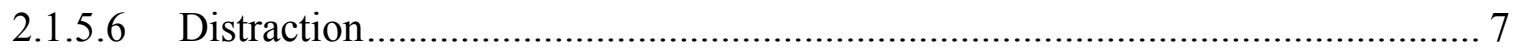

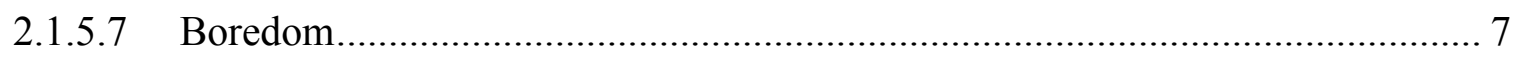

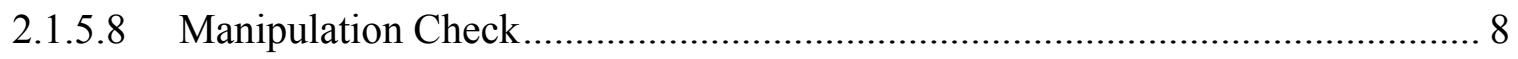

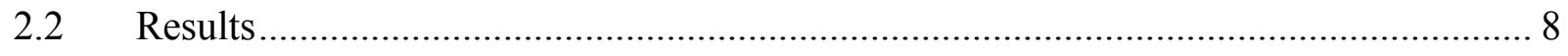

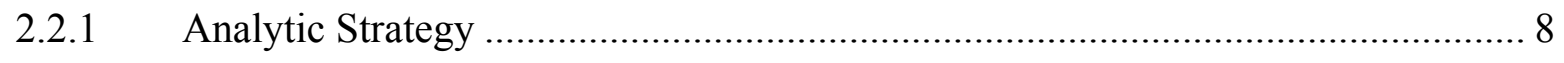

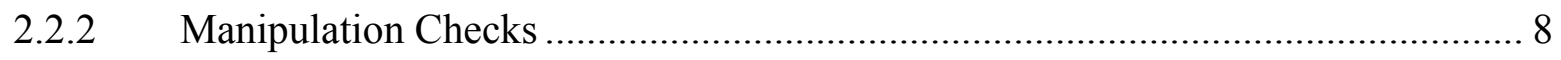

2.2.3 Preregistered Hypotheses ........................................................................... 9

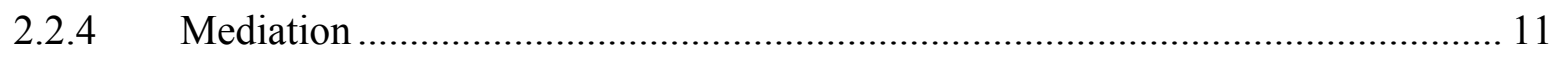

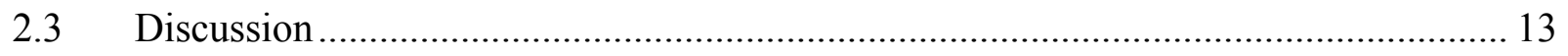

Chapter 3: Experience Sampling Study ..............................................................................................14

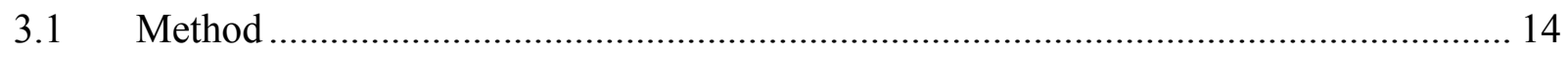

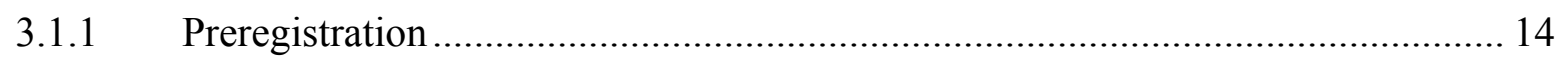

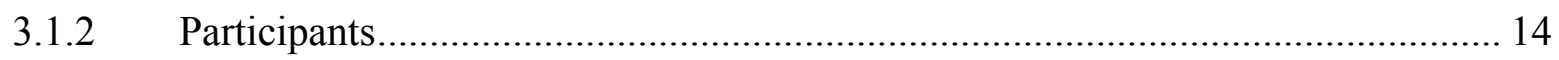

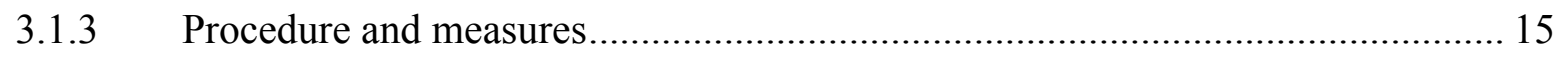

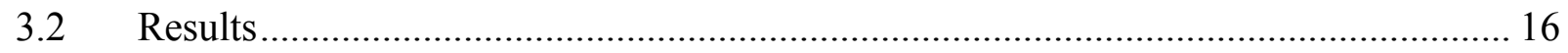

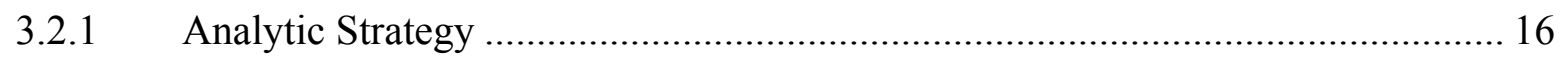

3.2.2 Effects of Phone Use.................................................................................... 16

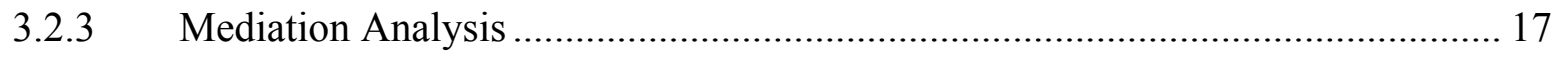

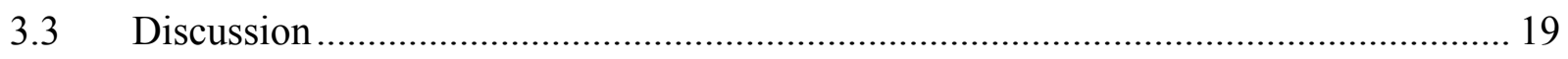

Chapter 4: Conclusion ..............................................................................................................................20 


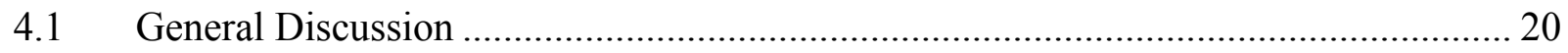

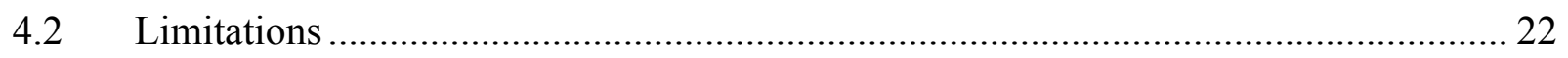

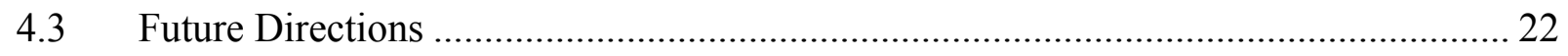

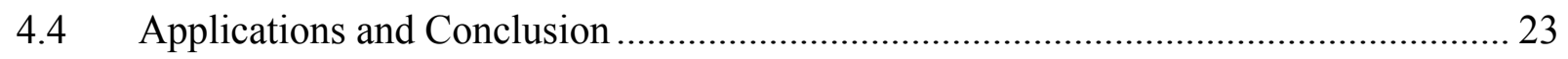

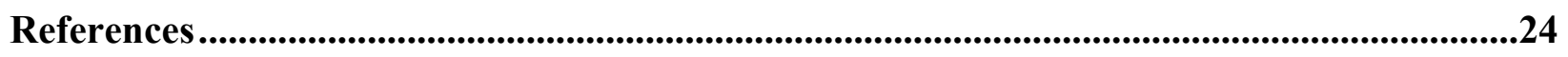

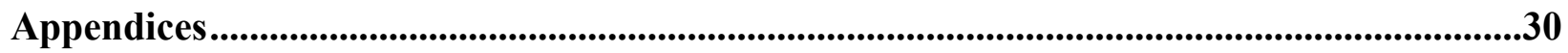

Appendix A Multilevel Models for All Dependent Variables in Study 1 ........................... 30

Appendix B Phone Use Composite Correlated with All Dependent Variables in Study 1 ...... 34

Appendix C Multilevel Models Predicting Distraction from Phone Use in Study 2............. 36 


\section{List of Tables}

Table 1. Means and Standard Deviations for Measures in Study 1 ...................................... 10

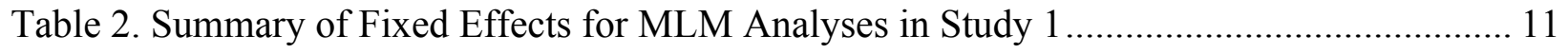

Table 3. Mediational and Indirect Effects of Phone Use Through Distraction in Study 1 .......... 12

Table 4. Means for Episodes With Phone Use Versus No Phone Use in Study 2.................... 17

Table 5. Indirect Effects of Phone Use Through Distraction in Study 2 ................................ 18 


\section{Acknowledgements}

I would like to thank my advisor, Dr. Elizabeth Dunn, for her guidance, support, and enduring positivity. I am grateful to my committee, Dr. Alan Kingstone and Dr. Kristin Laurin, for their time and insight. Several UBC Psychology faculty have provided me valuable feedback and mentorship throughout my degree, including Dr. Steve Heine and Dr. Jiaying Zhao. I would also like to acknowledge the support of fellow students Dr. Aaron Weidman, Dr. Grace Truong, and Dr. Kostadin Kushlev, who have provided statistical advice on this and other research projects. A special thanks to Jena Greenburg, who has made many sacrifices in support of my goals (like moving to another country), and to my family, who remind me that I can move back anytime. Finally, thank you to the many research assistants, whose instrumental help made this work possible: Camille Hunt, Charlotte Freitag, Kara Lee, Nishi Sumant, Shauna Moore, Zoe Bethune, Tara Arvan, Briana Nolletti, Remy Panikkar, Luan Wei, Bahja Ammari, and Allison Yang. 


\section{Dedication}

To my family. We love our phones almost as much as we love each other. 


\section{Chapter 1: Introduction}

\subsection{Social Interactions}

Decades of research on human happiness points to one central conclusion: Engaging in positive social interactions is critical for well-being (Baumeister \& Leary, 1995; Epley \& Schroder, 2014; Kahneman, Krueger, Schkade, Schwarz, \& Stone, 2004; Sandstrom \& Dunn, 2014). But the current technological revolution may be altering how and when we derive these benefits. Smartphones enable us to connect with friends and family throughout the day, potentially allowing us to reap the benefits of social interactions even when we are alone. But could these devices — with their ability to connect us with anyone, anywhere - distract us from enjoying interactions with the people sitting right next to us?

\subsection{Potential Psychological Costs of Phone Use}

In a recent Pew study, almost $90 \%$ of cell phone owners reported using their phones during their most recent social activity (Pew Research Center, 2015). Multi-tasking by using phones may be a major source of distraction in daily life, leaving people unable to concentrate fully on their primary activity. For example, using phones while driving is comparable to driving drunk (Strayer, Drews, \& Crouch, 2006), and using phones in the classroom has been shown to impede learning (Wood et al., 2012). Theoretically, distraction should also reduce the ability to derive pleasure from positive experiences (Brown \& Ryan, 2003; Quoidbach et al, 2010). Several studies lend support to this contention (e.g., Csikszentmihalyi, 1990; LeBel \& Dubé, 2001), although this idea has not been tested directly. In addition to increasing distraction, phones may compromise the benefits of social interactions by increasing perceived opportunity costs; texting a romantic partner during lunch with friends or peeking at a work email during a family dinner may remind people of the other things they want or need to be doing. Thus, 
researchers have theorized that the mere presence of phones may orient people away from their immediate social environment, potentially decreasing enjoyment of social interactions (Przybylski \& Weinstein, 2012; Srivastava, 2005). In sum, by increasing feelings of distraction or perceived opportunity costs, smartphone use may undermine the emotional benefits people derive from social interactions.

\subsection{Potential Psychological Benefits of Phone Use}

It is also possible, however, that phone use could play a positive role in social interactions. When a conversation lags or turns to dull topics, smartphones could provide reliable access to an array of brief engaging activities. Researchers have theorized that engaging one's attention with desired stimuli should decrease boredom, speed the passage of time, and promote a sense of agency (for a review, see Eastwood, Frischen, Fenske, \& Smilek, 2012). By allowing us to engage our attention with an array of stimuli on demand, therefore, phones may decrease boredom, make time pass more quickly, and give us a greater sense of control.

\subsection{Past Research and Current Approach}

There is abundant speculation about the possible effects of phones on social interactions (Turkle, 2012, 2015), but research examining how phone use shapes the benefits people derive from social interactions is in its infancy. Using correlational analyses, recent studies have documented a negative relationship between the presence of phones and the quality of social interactions (Brown, Manago, \& Trimble, 2016; Misra, Cheng, Genevie, \& Yuan, 2014), and

these studies are supported by similar findings in the lab (Przybylski \& Weinstein, 2012; Vanden Abeele, Antheunis, \& Schouten, 2016). However, no research has experimentally manipulated phone use in the real world, and research has yet to document the psychological mechanisms underlying the effects of phone use on the rewards derived from social interactions. 
Thus, in Study 1, we conducted a field experiment in which we manipulated phone use during a central social activity — sharing a meal out with friends and family. In Study 2, we used experience sampling to capture the relationship between phone use and well-being across a wider range of social contexts over the course of a week. In both studies, we examined whether and how phone use affects the social and emotional benefits people reap during in-person social interactions. In line with current best practices, we preregistered both studies, and we report all measures, conditions, and exclusions, as well as how sample sizes were determined. 


\section{Chapter 2: The Restaurant Study}

\subsection{Method}

\subsubsection{Preregistered power analysis}

Based on a pilot study, we estimated an effect size of $d=.4$; using $\mathrm{G}^{*}$ Power3, we calculated that we would need a sample size of $\mathrm{N}=200$ for $80 \%$ power, which we preregistered on the Open Science Framework (OSF) at http://tinyurl.com/hwmo9t6. Given the high costs of this study, we planned and preregistered sequential analyses at $\mathrm{N}=100,200$, and 300 (Lakens, 2014). The results of our interim analyses led us to continue collecting data until we reached $\mathrm{N}=$ 300; to control the Type 1 error rate, we calculated and preregistered an adjusted alpha-level of .0278 .

\subsubsection{Participants}

Because sessions were scheduled ahead of time, we slightly surpassed our target sample size, with 304 participants $(64 \%$ females, ages $=19-69, \mathrm{M}=29.9$ years, $\mathrm{SD}=10.6)$. The sample included both university students (34\%) and adults from the Vancouver, BC community (66\%). An additional 2 participants did not have usable data due to a technical error that occurred while completing the survey. We required that all participants own a smartphone, ostensibly so that they could receive study-related reminders and survey questions.

\subsubsection{Procedure}

Participants were invited to complete a "study investigating people's experience dining out with friends." Groups of 3-5 friends or family members participated in the study at a local café. After providing consent, each group was randomly assigned to the phone or phoneless condition. To manipulate phone use without revealing the purpose of the study, we told participants in the phone condition that they would be asked to answer a survey question after 
ordering their food, and that the RA would text them this question; to ensure that they received the survey, they were told to set their phone on the table with the ringer or vibration on. In the phoneless condition, participants were also told that they would answer a survey question, which would be handed to them on paper; these participants were then instructed to turn their phones on silent and place them in a container on the table. To support our cover story, we asked participants to rate how they were feeling that day on a scale from 0 to 100 via text (phone condition) or paper (phoneless condition). Participants then ate their meal together without further interruption by the experimenter.

After their meal, all participants were given iPads to complete a questionnaire (thereby maximizing the privacy of their responses; for complete survey see http://tinyurl.com/hwmo9t6). This questionnaire included our key measures of social connectedness, affect, opportunity costs, interest/enjoyment, distraction, perceived control, time perception, and boredom, in that order. Next, participants were asked to answer questions about their overall amount of phone use during the session (providing a manipulation check); we also included exploratory questions about the nature of their phone use (e.g., text messaging, social media, photos). Finally, participants were asked to indicate the nature of their relationship to each other person in the group (e.g., spouse, sibling, friend), and to provide demographics. After completing this survey, participants were asked to provide feedback about the study and to report how many notifications they received on their phones. All sessions were videotaped using a small camera positioned so that it was visible but unobtrusive.

\subsubsection{Preregistered Hypotheses}

We preregistered our main hypotheses at the Open Science Framework (http://tinyurl.com/hwmo9t6). Specifically, we predicted that phone use would undermine the 
benefits people derived from sharing a meal with others, such that participants in the phone (vs. phoneless) condition would experience less social connectedness, more tense arousal, less pleasant affect, and less interest/enjoyment. We expected that these negative effects would be mediated by distraction or by perceived opportunity costs. We also anticipated that phone use would provide benefits by giving people a greater sense of perceived control, reducing boredom, and making time seem to move faster. We expected that the positive and negative effects of being assigned to the phone condition would be amplified for individuals who used their phones heavily during the meal.

\subsubsection{Measures}

\subsubsection{Social Connectedness}

To measure state social connectedness, we adapted 8 items $(\alpha=.77)$ from the Social Connectedness Scale - Revised (Lee, Draper, \& Lee, 2001); we selected the highest-loading items that were not trait-like or extreme. ${ }^{1}$ Participants rated their agreement with statements such as "I felt close to people" on a scale from Strongly disagree (1) to Strongly agree (7).

\subsubsection{Affect}

We measured affect using Schimmack \& Grob's (2000) 18-item scale, which includes subscales of mood valence (e.g., pleasant; $\alpha=.87$ ) and tense arousal (e.g., jittery; $\alpha=.72$ ), as well as energetic arousal (e.g., awake; $\alpha=.90$ ), which we included as an exploratory measure. Participants rated their feelings on a scale from Not at all (1) to Very much (7).

\footnotetext{
${ }^{1}$ We originally included one fairly extreme item, "I saw myself as a loner," but replaced this item with less extreme item after the first 10 participants to minimize potential floor effects. Results are substantively unchanged upon inclusion or exclusion of this item.
} 


\subsubsection{Opportunity Cost}

We measured perceived opportunity costs by asking participants, "To what extent did you feel there were other things that you wanted or needed to be doing?" on a scale from Not at all (1) to Very much (7).

\subsubsection{Interest and Enjoyment}

To capture interest and enjoyment, we adapted three items $(\alpha=.69)$ from the Interest and Enjoyment subscale of the Intrinsic Motivation Inventory (Ryan, 1982), which was developed to capture individuals' subjective experiences related to a specific target activity (such as laboratory tasks). Participants rated their agreement with items such as "I enjoyed this experience very much" on a scale from Not at all true (1) to Very true (7).

\subsubsection{Perceived Control}

To measure perceived control, we adapted a 5-item scale $(\alpha=.61)$ used previously by Bernstein and Claypool (2012). Participants rated their agreement with items such as "I felt I had control” on a scale from Strongly disagree (1) to Strongly agree (7).

\subsubsection{Distraction}

To capture distraction, we adapted the two most relevant items $(\alpha=.54)$ from the attention subscale of the Cognitive and Affective Mindfulness Scale- Revised (Feldman et al., 2006). Participants rated their agreement with the items "It was easy for me to concentrate on what I was doing" and "I was easily distracted" on a scale from Not at all true (1) to Very true (7).

\subsubsection{Boredom}

To capture boredom, we adapted four items $(\alpha=.83)$ from the disengagement subscale of of the Multidimensional State Boredom Scale (Fahlman et al., 2015), such as "I felt bored.” In 
addition, to capture the related dimension of time moving slowly, we included three items $(\alpha=$ .88) from the time perception subscale, such as "Time was dragging on." Participants rated their agreement with each statement from Strongly disagree (1) to Strongly agree (7).

\subsubsection{Manipulation Check}

We asked participants to report "During the dining experience today, how often did you use your mobile phone?" from Not at all (1) to Constantly (7). To capture phone use compared to participants' normal behavior, we asked "How frequently did you use your phone as compared to how you would have normally used your phone in a restaurant with your friends/family?" from Much less (-3) to Much more (3). To provide an objective behavioral measure, the amount of time participants spent interacting with their phones was assessed by two coders, and then divided by the total duration of the video. Coders showed high agreement $(\alpha=.95)$ and thus we averaged their ratings.

\subsection{Results}

\subsubsection{Analytic Strategy}

Because all participants within a group were assigned to the same condition, we employed multilevel modeling (MLM), which accounts for non-independence. We used SPSS 24 to run all reported mixed models. For all of the models, we used maximum likelihood estimation and treated predictors as fixed effects, allowing only the intercept to vary as a random effect at the person level. The reported fixed effects below represent the effect of Condition (level-2 variable) on participants' feelings and behavior (level-1 variables).

\subsubsection{Manipulation Checks}

Confirming the success of our manipulations, participants in the phone condition reported using their phones more during the study $(\mathrm{M}=2.21, \mathrm{SD}=1.31)$ than those in the phoneless 
condition $(\mathrm{M}=1.07, \mathrm{SD}=.31), b=1.16, t(73.45)=8.79, p<.001$. Participants in the phone condition reported using their phones slightly less than normal $(\mathrm{M}=-.63, \mathrm{SD}=1.24)$, while participants in the phoneless condition reported using their phones much less than normal $(\mathrm{M}=$ $1.79, \mathrm{SD}=1.44)$, creating a significant difference between conditions, $b=1.16, t(72.02)=7.31$, $p<.001$. Additionally, coders' objective ratings confirmed that participants in the phone condition used their phones for a greater percentage of time during the sessions $(\mathrm{M}=11 \%, \mathrm{SD}=$ $8 \%)$ compared to those in the phoneless condition $(\mathrm{M}=1 \%, \mathrm{SD}=2 \%), b=.11, t(79.31)=10.02$, $p<.001$.

\subsubsection{Preregistered Hypotheses}

Consistent with our preregistered hypothesis, participants in the phone condition reported significantly lower interest and enjoyment than those in the phoneless condition, $b=-.37$, $t(82.75)=-2.55, p=.013$ (see Table 1 and Table 2). Participants in the phone (vs. phoneless) condition also reported feeling more distracted, $b=.46, t(79.08)=3.14, p=.002$. In contrast to our original prediction— but consistent with the other negative effects of phone use — participants reported marginally higher boredom, $b=.28, t(77.06)=2.15, p=.035$. Similarly, participants in the phone (vs. phoneless) condition reported worse subjective experience on all of our other dependent variables, although these effect were not significant. ${ }^{2}$

\footnotetext{
${ }^{2}$ We also predicted that the negative effects of phone use would be amplified for participants who exhibited the highest levels of phone use. We did not find consistent support for this hypothesis (see SOM).
} 
Table 1. Means and Standard Deviations for Measures in Study 1

\begin{tabular}{|c|c|c|c|c|}
\hline \multirow[b]{2}{*}{ Primary Dependent Variables } & \multicolumn{2}{|c|}{ Phone $(n=152)$} & \multicolumn{2}{|c|}{ Phoneless $(n=152)$} \\
\hline & Mean & $S D$ & Mean & $S D$ \\
\hline Social Connectedness & 5.78 & .82 & 5.82 & .79 \\
\hline Valence & 5.99 & .89 & 6.12 & .82 \\
\hline Tense Arousal & 2.65 & .97 & 2.55 & .88 \\
\hline Energetic Arousal & 4.8 & 1.23 & 5.05 & 1.2 \\
\hline Interest/Enjoyment & 4.98 & 1.17 & 5.36 & 1.02 \\
\hline Control & 4.85 & .84 & 4.97 & .94 \\
\hline Boredom & 2.21 & 1.19 & 1.93 & 1.02 \\
\hline Time Perception & 2.04 & 1.17 & 1.85 & 1.1 \\
\hline Mediator Variables & Mean & $S D$ & Mean & $S D$ \\
\hline Opportunity Cost & 2.84 & 1.66 & 2.92 & 1.63 \\
\hline Distraction & 2.84 & 1.2 & 2.38 & 1.03 \\
\hline
\end{tabular}


Table 2. Summary of Fixed Effects for MLM Analyses in Study 1

\begin{tabular}{lcccc}
\hline DV & $b$ & $d f$ & $t$ & $p$ \\
\hline Social Connectedness & -.03 & 80.52 & -.31 & .758 \\
Valence & -.12 & 79.72 & -1.14 & .257 \\
Tense Arousal & .1 & 83.01 & .9 & .369 \\
Energetic Arousal & -.25 & 79.96 & -1.64 & .106 \\
Interest/Enjoyment & -.37 & 82.75 & -2.55 & .013 \\
Control & -.11 & 81.66 & -1 & .323 \\
Boredom & .28 & 77.06 & 2.15 & .035 \\
Time Perception & .18 & 75.17 & 1.31 & .194 \\
\hline
\end{tabular}

Note. See Appendix A for Full Model Statistics.

\subsubsection{Mediation}

Because mediation analyses in multi-level models can be difficult to interpret, we conducted all mediation analyses at the group level by calculating mean scores on each variable for each group; we used Hayes’ (2016) PROCESS v2.15 for SPSS (Model 4), applying bootstrapping with 5,000 resamples. Although we originally predicted that distraction and opportunity costs might mediate the effects, condition only affected distraction, $b=.46, p=$ .003. In turn, distraction significantly predicted interest/enjoyment, $b=-.28, p=.002$. Thus, we examined whether distraction mediated the effect of condition on interest and enjoyment. Indeed, we found an indirect effect of condition on interest/enjoyment through distraction, $b=-.13, \mathrm{Z}=$ $1.98, p=.047$, which was marginal by our more stringent alpha level. Importantly, condition was no longer a significant predictor of interest and enjoyment after controlling for distraction, $b$ 
$=-.21, p=.144$, suggesting that the negative effect of phone use on interest/enjoyment was due in part to people being distracted by their phones.

Our manipulation also had significant indirect effects, via distraction, on nearly all of our dependent measures; that is, the presence of phones led people to feel more distracted, which in turn was associated with less positive affect valence, more tense arousal, less energetic arousal, less control, and more boredom (see Table 3).

Table 3. Mediational and Indirect Effects of Phone Use Through Distraction in Study 1

\begin{tabular}{lcccccc}
\hline & & & & \multicolumn{3}{c}{ Indirect Effect } \\
\cline { 5 - 6 } Outcome Variable & Path $b$ & Path $c$ & Path $c$ & $a^{*} b$ & $95 \% \mathrm{CI}$ & Sobel Z \\
\hline Social Connectedness & $-.21^{* *}$ & -.01 & .09 & -.1 & {$[-.23,-.02]$} & $-2.06 \dagger$ \\
Valence & $-.38^{* * *}$ & -.11 & .07 & -.18 & {$[-.36,-.07]$} & $-2.63^{* *}$ \\
Tense Arousal & $.44^{* * *}$ & .1 & -.1 & .2 & {$[.07, .38]$} & $2.7^{* *}$ \\
Energetic Arousal & $-.39 * * *$ & -.27 & -.09 & -.18 & {$[-.4,-.04]$} & $-2.27^{*}$ \\
Opportunity Cost & $.68^{* * *}$ & -.06 & -.37 & .31 & {$[.09, .64]$} & $2.34^{*}$ \\
Interest/Enjoyment & $-.28^{* *}$ & $-.34 *$ & -.21 & -.13 & {$[-.31,-.03]$} & $-1.98 \dagger$ \\
Control & $-.3 * * *$ & -.1 & .04 & -.14 & {$[-.3,-.05]$} & $-2.34^{*}$ \\
Boredom & $.44^{* * *}$ & .26 & .06 & .2 & {$[.07, .41]$} & $2.56^{*}$ \\
Time Perception & .19 & .16 & .07 & .09 & {$[-.01, .26]$} & 1.49 \\
\hline
\end{tabular}

Note. Mediation analyses were conducted at the group level by calculating mean scores on each variable for each group. The effect of Condition on Distraction (path $a$ ) is significant for all DV's, $b=.46, p=.003$. Path $b$ represents the effect of Distraction on each Outcome Variable. Path $c$ represents the total effect of Phone Use on each Outcome Variable. Path $c$ ' represents the direct effect of Phone Use on each Outcome Variable. $\dagger \mathrm{p}<.05 . * \mathrm{p}<.027 . * * \mathrm{p}<.01 . * * * \mathrm{p}<.001$. 


\subsection{Discussion}

In the real-world setting of a café, we found that people enjoyed a meal with their friends less when phones were present than when phones were put away. They also felt more distracted when phones were present (vs. absent), which had negative downstream consequences for their broader subjective experience (e.g., more tense arousal and boredom). Taken together, these results provide initial evidence that phone use may undermine some of the benefits people derive from the central social experience of sharing a meal. However, given that the effects were somewhat weak statistically and that we examined only one social setting, we conducted a second study examining phone use, distraction, and well-being across diverse social interactions. By using a within-subjects design and collecting data across numerous time points, we sought to enhance power to detect the effects initially observed in our between-subjects experiment. 


\section{Chapter 3: Experience Sampling Study}

In Study 1, we found experimental evidence that phone use during an enjoyable social activity caused people to feel distracted, which in turn led to a variety of negative downstream consequences for well-being. In Study 2, we built on these findings by investigating the effects of phone use during social interactions across a variety of situations. In this study, we surveyed people randomly 5 times a day for one week, asking them to report how they had been feeling and what they had been doing over the past 15 minutes.

\subsection{Method}

\subsubsection{Preregistration}

We preregistered our hypotheses and analysis plan on the Open Science Framework (http://tinyurl.com/z7xe43d). Based on Study 1, we predicted that during social interactions, people would feel more distracted and would experience less enjoyment when they were using smartphones compared to when they were not using smartphones. In addition, consistent with Study 1, we expected that phone use would have detrimental indirect effects (via distraction) on social connectedness, affect valence, boredom, and time perception. Because we planned to use multilevel modeling, traditional power analyses did not apply. We thus preregistered to collect at least 100 usable participants with replacement. Participants were considered unusable for the analyses if they had no episodes when they interacted with others in person.

\subsubsection{Participants}

Students at a large public university in the U.S. who owned smartphones participated for course credit. In total, 125 participants completed at least one ESM survey (Mean age $=18.6$, 
$69 \%$ women $)^{3}$. Of those, 2 had no episodes when they were interacting with others face-to-face. Thus, we report analyses from 123 usable participants. The participants responded to a total of 3008 ESM surveys, of which 1244 were episodes when they were interacting with others face-toface.

\subsubsection{Procedure and measures}

Participants completed a demographic survey, and on the following day, they began to receive text messages containing a link to a brief ESM survey. For seven days, participants received five prompts per day between 9am and 9pm. Within this 12-hour period, the prompts were sent randomly within five equally divided intervals. Each message instructed participants to respond as quickly as they safely could. The links expired after 1 hour, and each survey was administered at least 2 hours after the previous prompt.

At the top of each survey, participants were instructed that all the questions pertained to their experience "over the last 15 minutes before completing the survey." Participants then completed brief versions (adapted for ESM) of selected measures from Study 1. Specifically, participants reported whether they had enjoyed their experience in the last 15 minutes and whether they would describe their experience as very interesting $(1-$ Not true; 7 -Very true). We averaged these two responses to form our composite measure of interest/enjoyment ( $\alpha=$ .80). Affect valence, social connectedness, distraction, boredom, and time perception were each measured on 7-point scales using single items adapted from Study 1; for the full survey, see http://tinyurl.com/hau2wck.

${ }^{3}$ An additional 8 participants signed the consent form, but did not complete any ESM surveys. 
At the end of the survey, participants were asked what they had been doing in the past 15 minutes, including how much they had used their smartphones $(1-$ Not at all; 7 - Constantly). As preregistered based on the findings in Study 1, this measure was transformed into a dichotomous measure of whether or not people used their phones during the episode. Participants also indicated whether or not they had "socialized in person/face-to-face," amongst a number of other common daily activities (e.g., eating/drinking, working/studying).

\subsection{Results}

\subsubsection{Analytic Strategy}

We pre-registered our analysis plan on OSF; see http://tinyurl.com/z7xe43d. Because each person had multiple episodes, we used multilevel modeling (MLM) to estimate the effects. For all of the models, we used SPSS 21, specifying maximum likelihood estimation and treating predictors as fixed effects, allowing only the intercept to vary as a random effect at the person level $^{4}$.

\subsubsection{Effects of Phone Use}

As predicted, during episodes that included face-to-face social interactions, people reported feeling more distracted when they used their smartphones than when they did not, $b=$ $.95, p<.001$ (see Table 4 for means). In addition, during these episodes, participants experienced less interest and enjoyment when they used smartphones than when they did not, $b=-.41, p<$ .001. Although we did not predict direct effects of phone use on the other outcomes, we found that people also reported worse affect, $b=-.31, p<.001$, felt less socially connected, $b=-.33, p$ $<.001$, more bored, $b=.53, p<.001$, and perceived time to be moving slower, $b=.34, p=.001$

\footnotetext{
${ }^{4}$ Estimating the random component of each effect did not substantively change the size of the
} fixed component or the significance level. 
(see Appendix $\mathrm{C}$ for exhaustive list of model parameters for all reported models). In additional exploratory analyses, we used the continuous phone use variable as the predictor (1 - Not at all; 7 - Constantly) and found the same effects across all outcomes (all p’s $<.001)$.

Table 4. Means for Episodes With Phone Use Versus No Phone Use in Study 2

\begin{tabular}{|c|c|c|c|c|}
\hline & \multicolumn{2}{|c|}{ With Phone Use } & \multicolumn{2}{|c|}{ No Phone Use } \\
\hline & Mean & $S D$ & Mean & $S D$ \\
\hline Distraction & 3.45 & 0.91 & 2.42 & 1.26 \\
\hline Interest/Enjoyment & 4.78 & 1.01 & 5.33 & 1.25 \\
\hline Affect Valence & 5.28 & 0.98 & 5.77 & 1.11 \\
\hline Connectedness & 5.39 & 0.97 & 5.92 & 1.03 \\
\hline Boredom & 2.97 & 0.97 & 2.28 & 1.13 \\
\hline Time Perception & 3.11 & 1.11 & 2.70 & 1.53 \\
\hline
\end{tabular}

Note. In total, 120 people had episodes with phone use, whereas 96 people had episodes without phone use. This could explain why the standard deviations for episodes with phone use are smaller than those for episodes with no phone use.

\subsubsection{Mediation Analysis}

As preregistered, we used person-level means for the mediation analyses. For distraction and all outcome variables, we first aggregated each participant's scores separately for episodes with versus without smartphones. We then predicted the difference scores between the means of the outcome variables (e.g. interest/enjoyment) when people were using versus not using their phones from the difference and sum scores of distraction (i.e., the mediator). We employed the MEMORE macro (Montoya \& Hayes, in press) for SPSS to estimate the within-in subjects 
indirect effects using both normal-theory Sobel's Z and Monte Carlo confidence intervals (resampling 20,000 times).

We examined whether distraction could explain the effect of phone use on our outcome variables ${ }^{5}$. We found support for the mediating role of distraction across all outcomes (see Table 6). To the extent people felt more distracted when they used their phones, they reported feeling less enjoyment, worse affect, less socially connected, and more bored, as well as perceiving time as passing more slowly.

Table 5. Indirect Effects of Phone Use Through Distraction in Study 2

\begin{tabular}{lccccc}
\hline & & & \multicolumn{3}{c}{ Indirect Effect } \\
\cline { 4 - 6 } & Path $c$ & Path $c^{*}$ & $a^{*} b$ & $95 \% \mathrm{CI}$ & Sobel Z \\
\hline Interest/Enjoyment & $-.54^{* * *}$ & $-.30^{\dagger}$ & $-.24^{*}$ & {$[-.47,-.03]$} & -2.18 \\
Affect Valence & $-.46^{* * *}$ & -.20 & $-.26^{*}$ & {$[-.49,-.05]$} & -2.37 \\
Connectedness & $-.49^{* * *}$ & $-.30^{*}$ & $-.19^{\dagger}$ & {$[-.40, .00]$} & -1.90 \\
Boredom & $.70^{* * *}$ & $.28^{\dagger}$ & $.42^{* * *}$ & {$[.20, .66]$} & 3.58 \\
Time Perception & $.38^{*}$ & -.12 & $.50^{* * *}$ & {$[.26, .78]$} & 3.70 \\
\hline
\end{tabular}

Note. Path $c$ represents the total effect of Phone Use on each Outcome Variable. Path $c$ ' represents the direct effect of Phone Use on each Outcome Variable. All confidence intervals are based on Monte Carlo simulations using MEMORE macro.

$\mathrm{p}<.10 .{ }^{*} \mathrm{p}<.05 .{ }^{* *} \mathrm{p}<.01 .{ }^{* * *} \mathrm{p}<.001$ (significance based on Sobel's $\mathrm{Z}$ test of mediation)

${ }^{5}$ The sample used for the mediation analyses was smaller than the total sample because these analyses require people to have episodes both with and without reported phone use. The number of participants who had both episodes with reported distraction was $N=93$. As indicated by the total effects in Table 6, the effects of phone use on the outcome variables mirrored those from the MLM analyses reported above. 


\subsection{Discussion}

Across a variety of situations from daily life, we found that people reported feeling more distracted during social interactions when they used their phones than when they did not. During these episodes, people also experienced worse affect and more boredom, felt less socially connected, and perceived time to be moving slower. All of these negative outcomes were mediated through distraction, providing further evidence of our results from Study 1, and suggesting that phone use undermines the benefits derived from social interactions across many social situations. 


\section{Chapter 4: Conclusion}

\subsection{General Discussion}

Using a field experiment and intensive experience sampling, we found the first evidence that phone use undermines the enjoyment people derive from real world social interactions. In Study 1, phone use caused individuals to feel distracted, which reduced how much they enjoyed sharing a meal with friends at a local café. In Study 2, we obtained similar results by asking people to report what they had been doing and feeling during the past 15 minutes. When they had been engaging in face-to-face interactions, they felt more distracted and reported lower enjoyment if they had been using their smartphones than if they had not. Phone use also had indirect negative effects, via distraction, on other well-being outcomes; in both studies, phones made people feel distracted, which in turn predicted greater boredom and worse overall mood.

Going beyond previous research, we found these effects in naturalistic contexts by conducting a field experiment in a café and by using experience sampling to capture a variety of real-world social situations. These results held across two distinct samples, including both students and community members in Western Canada (Study 1), and students in the Southern United States (Study 2). It is especially notable that we observed negative effects of phone use among university students. This generation has grown up with mobile technology, and some have raised the possibility that young people might therefore be relatively adept at multi-tasking in real world contexts (Foehr, 2006). This idea is particularly compelling in the context of extended social interactions, such as sharing a meal with friends, given that natural lulls in conversation might afford the ability to attend to one's phone without any detectable cost. Yet, our findings suggest that even the moderate levels of phone use we observed are sufficient to create feelings of distraction that undermine the emotional rewards of social interaction. 
These results build on other recent work showing that phone use is associated with less positive social impressions (Vanden Abelee et al., 2016), lower interaction quality with friends (Brown et al., 2016; Misra et al., 2014), and lower relationship satisfaction with a romantic partner (Roberts \& David, 2016). We found that the negative effects of phone use were mediated by distraction, but not opportunity costs, suggesting that phone use prevents individuals from fully engaging in the present moment. Contrary to our original prediction, phones slightly increased boredom. While Eastwood et al. (2012) argue that interesting stimuli can decrease boredom, they also theorize that relatively subtle sources of distraction may lead people to misattribute their feelings of inattention to being bored with the situation. For example, people report greater boredom when a TV plays quietly in another room than when it is blaring (Damrad-Frye \& Laird, 1989). Thus, people may anticipate that phones will reduce boredom (as we did), but by providing a subtle source of distraction, phones may ironically increase boredom.

Still, it is important to note that the observed effects in the present study were relatively small. Phones may have minimal negative effects on individual social interactions; however, these small effects are likely consequential over time. McDaniel \& Coyne (2014) argue that small, frequent interruptions from phones can compound into relationship conflict and lower life satisfaction. Our study provides a window into one underlying process through which phone use may chip away at life satisfaction: phones may undermine the enjoyment derived from face-toface social interactions.

Of course, everyday life is riddled with other sources of distraction, such as newspapers and television, but phones differ from these earlier forms of information technology in two critical ways: Phones provide access to a virtually infinite array of potential diversions, while being so portable that they are almost always with us, enabling them to easily pervade our social 
interactions. For example, a recent observational study found that caregivers exhibited a high degree of absorption in their phones while sharing a meal with children at fast food restaurants (Radesky, Kistin, Augustyn, \& Silverstein, 2014). Theoretically, then, smartphones provide an ideal proxy for studying how the increasing pervasiveness of our digital activities is interacting with fundamental human activities (e.g., sharing a meal).

\subsection{Limitations}

Our studies have several limitations. Because participants in Study 1 were assigned to the phone or phoneless condition in groups, it is unclear whether the effects were caused by the individual's phone use, the phone use of others in the group, or an interaction between individual and group phone use. For example, Sally might become frustrated if all her friends are using their phones but she is not. Thus, an interesting open question is how individual and group phone use interact. It is also possible that some participants guessed the purpose of our studies, and thus responded according to their lay beliefs about phone use. In both studies, however, we ensured our interest in phone use was minimally salient by embedding any mention of phones within broader study instructions or questionnaire items.

\subsection{Future Directions}

Although we found that phone use negatively affected enjoyment of social interactions, phones should have positive effects in situations where distraction is desirable. Indeed, phone use has been found to reduce the need for anesthesia during minor surgery (Guillory, Hancock, $\&$ Woodruff, 2015). By affecting distraction, phones may also have a wide range of other psychological consequences. Distraction has been linked to reduced memory (Craik, Govoni, Naveh-Benjamin, \& Anderson, 1996), increased stress (Mark, 2008), and reduced self-control 
(Shiv \& Fedorikhin, 1999), pointing to the value of testing the effects of phone use on these outcomes.

\subsection{Applications and Conclusion}

Research on the cognitive effects of distraction have led governments to enact policy changes restricting phone use while driving (World Health Organization, 2011), and many course instructors have implemented analogous policies in their classrooms (Hammer et al., 2010). In a similar vein, our research highlights the need for change in social norms surrounding phone use in social interactions. In particular, this work reveals how phones can distract us from engaging with people in our immediate environment. Despite their ability to connect us to others across the globe, phones may undermine the benefits we derive from interacting with those across the table. 


\section{References}

Baumeister, R. F., \& Leary, M. R. (1995). The need to belong: Desire for interpersonal attachments as a fundamental human motivation. Psychological Bulletin, 117(3), 497529. http://doi.org/10.1037/0033-2909.117.3.497

Bernstein, M. J., \& Claypool, H. M. (2012). Not all social exclusions are created equal: Emotional distress following social exclusion is moderated by exclusion paradigm. Social Influence, 7(2), 113-130. http://doi.org/10.1080/15534510.2012.664326

Brown, G., Manago, A. M., \& Trimble, J. E. (2016). Tempted to text: College students mobile phone use during a face-to-face interaction with a close friend. Emerging Adulthood, 2-5. http://doi.org/10.1177/2167696816630086

Brown, K. W., \& Ryan, R. M. (2003). The benefits of being present: mindfulness and its role in psychological well-being. Journal of Personality and Social Psychology, 84(4), 822-848. http://doi.org/10.1037/0022-3514.84.4.822

Craik, F. I., Govoni, R., Naveh-Benjamin, M., \& Anderson, N. D. (1996). The effects of divided attention on encoding and retrieval processes in human memory. Journal of Experimental Psychology. General, 125(2), 159-180. http://doi.org/10.1037/0096-3445.125.2.159

Csikszentmihalyi, M. (1990). Flow: The psychology of optimal experience. New York, NY: Harper and Row.

Damrad-Frye, R., \& Laird, J. D. (1989). The experience of boredom: The role of the selfperception of attention. Journal of Personality and Social Psychology, 57(2), 315-320. 
http://doi.org/10.1037/0022-3514.57.2.315

Eastwood, J. D., Frischen, A., Fenske, M. J., \& Smilek, D. (2012). The unengaged mind: Defining boredom in terms of attention. Perspectives on Psychological Science, 7(5), 482-495. http://doi.org/10.1177/1745691612456044

Epley, N., \& Schroeder, J. (2014). Mistakenly seeking solitude. Journal of Experimental Psychology: General, 143(5), 1980-1999. http://doi.org/10.1037/a0037323

Fahlman, S. A., Mercer-Lynn, K. B., Flora, D. B., \& Eastwood, J. D. (2013). Development and validation of the multidimensional state boredom scale. Assessment, 20(1), 68-85. http://doi.org/10.1177/1073191111421303

Feldman, G., Hayes, A., Kumar, S., Greeson, J., \& Laurenceau, J. P. (2007). Mindfulness and emotion regulation: The development and initial validation of the Cognitive and Affective Mindfulness Scale- Revised (CAMS-R). Journal of Psychopathology and Behavioral Assessment, 29(3), 177-190.

Foehr, U. G. (2006). Media multitasking among American youth: Prevalence, predictors, and pairings. The Henry J. Kaiser Family Foundation, (December), 1-39.

Guillory, J. E., Hancock, J. T., \& Woodruff, C. (2015). Text messaging reduces analgesic text messaging reduces analgesic requirements during surgery. Pain Medicine, 16, 667-672. http://doi.org/10.1111/pme.12266

Hammer, R., Ronen, M., Sharon, A., Lankry, T., Huberman, Y., \& Zamtsov, V. (2010). Mobile culture in college lectures: Instructors' and students' perspectives. Interdisciplinary 
Journal of E-Learning \& Learning Objects, 6, 293-304.

Kahneman, D. (2003). A perspective on judgment and choice: mapping bounded rationality. The American Psychologist, 58(9), 697-720. Retrieved from http://www.ncbi.nlm.nih.gov/pubmed/14584987 on May 21, 2017.

Kahneman, D., Krueger, A. B., Schkade, D., Schwarz, N., \& Stone, A. A. (2004). A survey method for characterizing daily life experience: The day reconstruction method. Science (New York, N.Y.), 306(5702), 1776-1780. http://doi.org/10.1126/science.1103572

Konrath, S., Fuhrel-Forbis, A., Lou, A., \& Brown, S. L. (2012). Motives for volunteering are associated with mortality risk in older adults. Health Psychology, 31(1), 87-96. http://doi.org/10.1037/a0025226

Kushlev, K. (2011). Exploring parental well-being: Is childcare associated with parental well being and what factors can enhance it? Unpublished master's thesis, University of British Columbia, Vancouver, BC, Canada.

Lakens, D. (2014). Performing high-powered studies efficiently with sequential analyses. European Journal of Social Psychology, pp. 701-710. http://doi.org/10.1002/ejsp.2023

LeBel, J. L., \& Dubé, L. (2001). The impact of sensory knowledge and attentional focus on pleasure and on behavioral responses to hedonic stimuli. 13th Annual American Psychological Society Convention.

Lee, R. M., Draper, M., \& Lee, S. (2001). Social connectedness, dysfunctional interpersonal behaviors, and psychological distress: Testing a mediator model. Journal of Counseling 
Psychology, 48(3), 310-318. http://doi.org/10.1037/0022-0167.48.3.310

Mark, G., Gudith, D., \& Klocke, U. (2008, April). The cost of interrupted work: More speed and stress. In Proceedings of the SIGCHI conference on Human Factors in Computing Systems (pp. 107-110). ACM.

McDaniel, B. T., \& Coyne, S. M. (2014). “Technoference”: The interference of technology in couple relationships and implications for women's personal and relational well-being. Psychology of Popular Media Culture, 5(1). http://doi.org/10.1037/ppm0000065

Misra, S., Cheng, L., Genevie, J., \& Yuan, M. (2014). The iPhone effect: The quality of inperson social interactions in the presence of mobile devices. Environment and Behavior, 1-24. http://doi.org/10.1177/0013916514539755

Montoya, A. K., \& Hayes, A. F. (in press). Two condition within-participant statistical mediation analysis: A path-analytic framework. Psychological Methods.

Pew Research Center (2015). Americans' views on mobile etiquette. Retrieved from http://www.pewinternet.org/2015/08/26/americans-views-on-mobile-etiquette/ on September 12, 2016.

Przybylski, a. K., \& Weinstein, N. (2012). Can you connect with me now? How the presence of mobile communication technology influences face-to-face conversation quality. Journal of Social and Personal Relationships, 30(3), 237-246. http://doi.org/10.1177/0265407512453827

Quoidbach, J., Berry, E. V., Hansenne, M., \& Mikolajczak, M. (2010). Positive emotion 
regulation and well-being: Comparing the impact of eight savoring and dampening strategies. Personality and Individual Differences, 49(5), 368-373. http://doi.org/10.1016/j.paid.2010.03.048

Radesky, J. S., Kistin, C. J., Augustyn, M., \& Silverstein, M. (2014). Patterns of Mobile Device Use by Caregivers and Children During Meals in Fast Food Restaurants. Pediatrics, 133(4), e843-e849. http://doi.org/10.1542/peds.2013-3703

Roberts, J. A., \& David, M. E. (2016). My life has become a major distraction from my cell phone: Partner phubbing and relationship satisfaction among romantic partners. Computers in Human Behavior, 54, 134-141. http://doi.org/10.1016/j.chb.2015.07.058

Ryan, R. M. (1982). Control and information in the intrapersonal sphere: An extension of cognitive evaluation theory. Journal of Personality and Social Psychology, 42(3), 450461.

Sandstrom, G. M., \& Dunn, E. W. (2014). Social interactions and well-being: The surprising power of weak ties. Personality \& Social Psychology Bulletin, 40(7), 910-922. http://doi.org/10.1177/0146167214529799

Schimmack, U., \& Grob, A. (2000). Dimensional models of core affect: A quantitative comparison by means of structural equation modelling. European Journal of Personality, $14,325-345$.

Shiv, B., \& Fedorikhin, A. (1999). Heart and mind in conflict: The interplay of affect and cognition in consumer decision making. Journal of Consumer Research, 26(3), 278-292. 
http://doi.org/10.1086/209563

Srivastava, L. (2005). Mobile phones and the evolution of social behaviour. Behaviour \& Information Technology, 24(2), 111-129. http://doi.org/10.1080/01449290512331321910

Strayer, D. L., Drews, F. A., \& Crouch, D. J. (2006). A comparison of the cell phone driver and the drunk driver. Human Factors, 48(2), 381-91. http://doi.org/10.1518/001872006777724471

Turkle, S. (2012). Alone together: Why we expect more from technology and less from each other. New York, NY: Basic Books.

Turkle, S. (2015). Reclaiming conversation: The power of talk in a digital age. Penguin Press.

Vanden Abeele, M. M. P., Antheunis, M. L., \& Schouten, A. P. (2016). The effect of mobile messaging during a conversation on impression formation and interaction quality. Computers in Human Behavior, 62, 562-569. http://doi.org/10.1016/j.chb.2016.04.005

Wood, E., Zivcakova, L., Gentile, P., Archer, K., De Pasquale, D., \& Nosko, A. (2012). Examining the impact of off-task multi-tasking with technology on real-time classroom learning. Computers and Education, 58(1), 365-374. http://doi.org/10.1016/j.compedu.2011.08.029

World Health Organization. (2011). Mobile phone use: A growing problem of driver distraction. World Health Organization. Retrieved from http://www.who.int/violence_injury_prevention/publications/road_traffic/distracted_drivi ng_en.pdf on November 15, 2016. 


\section{Appendices}

Appendix A Multilevel Models for All Dependent Variables in Study 1

Table A1. Multilevel Models for All Dependent Variables in Study 1

\begin{tabular}{|c|c|c|c|c|c|}
\hline & \multicolumn{5}{|c|}{ Measure: Connectedness } \\
\hline & Estimate & $S E$ & $d f$ & $t$ & $p$ \\
\hline \multicolumn{6}{|l|}{ Fixed effects } \\
\hline Intercept $\left(\beta_{00}\right)$ & 5.82 & .07 & 81.97 & 81.66 & .000 \\
\hline \multirow{2}{*}{ Condition $\left(\beta_{1 j}\right)$} & -.03 & .10 & 80.52 & -.31 & .758 \\
\hline & & & & Wald Z & \\
\hline \multicolumn{6}{|l|}{ Random effects } \\
\hline Intercept $\left(\mu_{0 j}\right)$ & .05 & .03 & & 1.36 & .174 \\
\hline \multirow[t]{3}{*}{ Residual $\left(\varepsilon_{i j)}\right.$} & .59 & .06 & & 10.64 & .000 \\
\hline & \multicolumn{5}{|c|}{ Measure: Valence } \\
\hline & Estimate & $S E$ & $d f$ & $t$ & $p$ \\
\hline \multicolumn{6}{|l|}{ Fixed effects } \\
\hline Intercept $\left(\beta_{00}\right)$ & 6.12 & .08 & 81.13 & 79.94 & $<.001$ \\
\hline \multirow[t]{2}{*}{ Condition $\left(\beta_{1 j}\right)$} & -.12 & .11 & 79.72 & -1.14 & .257 \\
\hline & & & & Wald Z & \\
\hline \multicolumn{6}{|l|}{ Random effects } \\
\hline Intercept $\left(\mu_{0 j}\right)$ & .06 & .04 & & 1.43 & .153 \\
\hline Residual $\left(\varepsilon_{i j)}\right.$ & .67 & .06 & & 10.61 & $<.001$ \\
\hline
\end{tabular}


Measure: Tense Arousal

$\begin{array}{lllll}\text { Estimate } & S E & d f & t\end{array}$

\begin{tabular}{|c|c|c|c|c|c|}
\hline \multicolumn{6}{|l|}{ Fixed effects } \\
\hline Intercept $\left(\beta_{00}\right)$ & 2.55 & .08 & 84.48 & 31.09 & $<.001$ \\
\hline \multirow[t]{2}{*}{ Condition $\left(\beta_{1 j}\right)$} & .10 & .12 & 83.01 & .90 & .369 \\
\hline & & & & Wald Z & \\
\hline \multicolumn{6}{|l|}{ Random effects } \\
\hline Intercept $\left(\mu_{0 j}\right)$ & .06 & .04 & & 1.38 & .168 \\
\hline \multirow[t]{3}{*}{ Residual $\left(\varepsilon_{i j}\right)$} & .78 & .07 & & 10.69 & $<.001$ \\
\hline & \multicolumn{5}{|c|}{ Measure: Energetic } \\
\hline & Estimate & $S E$ & $d f$ & $t$ & $p$ \\
\hline \multicolumn{6}{|l|}{ Fixed effects } \\
\hline Intercept $\left(\beta_{00}\right)$ & 5.05 & .11 & 81.35 & 46.18 & .000 \\
\hline \multirow[t]{2}{*}{ Condition $\left(\beta_{1 j}\right)$} & -.25 & .15 & 79.96 & -1.64 & .106 \\
\hline & & & & Wald Z & \\
\hline \multicolumn{6}{|l|}{ Random effects } \\
\hline Intercept $\left(\mu_{0 j}\right)$ & .12 & .08 & & 1.52 & .129 \\
\hline \multirow[t]{3}{*}{ Residual $\left(\varepsilon_{i j}\right)$} & 1.34 & .13 & & 10.62 & .000 \\
\hline & \multicolumn{5}{|c|}{ Measure: Opportunity Cost } \\
\hline & Estimate & $S E$ & $d f$ & $t$ & $p$ \\
\hline \multicolumn{6}{|l|}{ Fixed effects } \\
\hline Intercept $\left(\beta_{00}\right)$ & 2.92 & .16 & 70.36 & 17.94 & .000 \\
\hline \multirow[t]{2}{*}{ Condition $\left(\beta_{1 j}\right)$} & -.07 & .23 & 71.66 & -.32 & .749 \\
\hline & & & & Wald Z & \\
\hline \multicolumn{6}{|l|}{ Random effects } \\
\hline Intercept $\left(\mu_{0 j}\right)$ & .41 & .19 & & 2.17 & .030 \\
\hline Residual $\left(\varepsilon_{i j}\right)$ & 2.28 & .23 & & 9.94 & .000 \\
\hline
\end{tabular}


Measure: Interest/Enjoyment

\begin{tabular}{lllll}
\hline Estimate & $S E$ & $d f$ & $t$ & $p$ \\
\hline
\end{tabular}

Fixed effects

Intercept $\left(\beta_{00}\right)$

$5.36 \quad .10$

84.08

53.09

$<.001$

Condition $\left(\beta_{1 j}\right)$

$-.37$

.14

82.75

$-2.55$

.013

Wald Z

Random effects

\begin{tabular}{|c|c|c|c|c|c|}
\hline Intercept $\left(\mu_{0 j}\right)$ & .12 & .07 & & 1.83 & .067 \\
\hline \multirow[t]{3}{*}{ Residual $\left(\varepsilon_{i j}\right)$} & 1.08 & .10 & & 10.67 & $<.001$ \\
\hline & \multicolumn{5}{|c|}{ Measure: Control } \\
\hline & Estimate & $S E$ & $d f$ & $t$ & $p$ \\
\hline \multicolumn{6}{|l|}{ Fixed effects } \\
\hline Intercept $\left(\beta_{00}\right)$ & 4.97 & .08 & 83.05 & 61.58 & .000 \\
\hline \multirow[t]{2}{*}{ Condition $\left(\beta_{1 j}\right)$} & -.11 & .11 & 81.66 & -1.00 & .323 \\
\hline & & & & Wald Z & \\
\hline \multicolumn{6}{|l|}{ Random effects } \\
\hline Intercept $\left(\mu_{0 j}\right)$ & .07 & .04 & & 1.60 & .110 \\
\hline \multirow[t]{3}{*}{ Residual $\left(\varepsilon_{i j}\right)$} & .72 & .07 & & 10.65 & .000 \\
\hline & \multicolumn{5}{|c|}{ Measure: Distraction } \\
\hline & Estimate & $S E$ & $d f$ & $t$ & $p$ \\
\hline \multicolumn{6}{|l|}{ Fixed effects } \\
\hline Intercept $\left(\beta_{00}\right)$ & 2.38 & .10 & 80.34 & 54.30 & .000 \\
\hline \multirow[t]{2}{*}{ Condition $\left(\beta_{1 j}\right)$} & .46 & .15 & 79.08 & 3.14 & .002 \\
\hline & & & & Wald Z & \\
\hline \multicolumn{6}{|l|}{ Random effects } \\
\hline Intercept $\left(\mu_{0 j}\right)$ & .14 & .07 & & 1.89 & .059 \\
\hline Residual $\left(\varepsilon_{i j}\right)$ & 1.10 & .10 & & 10.58 & .000 \\
\hline
\end{tabular}


Measure: Boredom

\begin{tabular}{|c|c|c|c|c|c|}
\hline & \\
\hline & Estimate & $S E$ & $d f$ & $t$ & $p$ \\
\hline \multicolumn{6}{|l|}{ Fixed effects } \\
\hline Intercept $\left(\beta_{00}\right)$ & 1.93 & .09 & 78.83 & 21.22 & .000 \\
\hline \multirow[t]{2}{*}{ Condition $\left(\beta_{1 j}\right)$} & .28 & .13 & 77.06 & 2.15 & .035 \\
\hline & \multicolumn{5}{|c|}{ Wald Z } \\
\hline \multicolumn{6}{|l|}{ Random effects } \\
\hline Intercept $\left(\mu_{0 j}\right)$ & .01 & .06 & & .23 & .820 \\
\hline \multirow[t]{3}{*}{ Residual $\left(\varepsilon_{i j}\right)$} & 1.21 & .11 & & 10.60 & .000 \\
\hline & \multicolumn{5}{|c|}{ Measure: Time Perception } \\
\hline & Estimate & $S E$ & $d f$ & $t$ & $p$ \\
\hline \multicolumn{6}{|l|}{ Fixed effects } \\
\hline Intercept $\left(\beta_{00}\right)$ & 1.86 & .10 & 76.70 & 19.04 & .000 \\
\hline \multirow[t]{2}{*}{ Condition $\left(\beta_{1 j}\right)$} & .18 & .14 & 75.17 & 1.31 & .194 \\
\hline & & & & Wald Z & \\
\hline \multicolumn{6}{|l|}{ Random effects } \\
\hline Intercept $\left(\mu_{0 j}\right)$ & .06 & .07 & & .86 & .392 \\
\hline Residual $\left(\varepsilon_{i j}\right)$ & 1.22 & .12 & & 10.52 & .000 \\
\hline
\end{tabular}




\section{Appendix B Phone Use Composite Correlated with All Dependent Variables in Study 1}

In Study 1, we preregistered that the extent to which participants used their phone during the study would moderate the negative effects of phone use on the emotional benefits derived from the social interaction (http://tinyurl.com/hwmo9t6). That is, we expected participants who used their phone relatively more would experience more negative consequences on our measures of well-being compared to those who used their phone relatively less. For participants in the phone condition, subjective phone use and phone use ratings from objective coders correlated $r=$ $0.47, p<.001$, so they were combined to form a composite phone use score. Phone use did not reliably predict stronger effects on our dependent variables (see table below). It is possible that the effects of phone use result from a combination of the phone use of the individual and the phone use of other group members. For example, phone use may be more detrimental when one group member is using their phone relatively more than the other group members. We conducted exploratory analyses to examine whether the phone use of each person interacted with the phone of the other group members. Individual phone use and group phone use were highly correlated, so due to multicollinearity our results were not reliable. Further research will be needed to explore this possible interaction. We also preregistered exploratory analyses to investigate whether individual differences in normal phone use would moderate our effects, however, this item was dropped from the final version of our questionnaire, so we do not have the data to test this question. 
Table A2. Phone Use Composite Score Correlated with All Dependent Variables in Study 1

(Phone Condition Only).

\begin{tabular}{lcc}
\hline Variable & $\mathrm{r}$ & Sig \\
\hline Social Connectedness & -.05 & .57 \\
Valence & -.09 & .28 \\
Tense Arousal & .03 & .71 \\
Energetic Arousal & -.05 & .56 \\
Opportunity Cost & .19 & .026 \\
Interest/Enjoyment & -.03 & .67 \\
Control & -.01 & .94 \\
Distraction & .09 & .29 \\
Boredom & .16 & .05 \\
Time Perception & .2 & .016 \\
\hline Note. & &
\end{tabular}

Note. $\mathrm{N}=152$. 
Appendix C Multilevel Models Predicting Outcomes from Phone Use in Study 2

Table A 3. Multilevel Models Predicting Outcomes from Phone Use in Study 2

\begin{tabular}{|c|c|c|c|c|c|c|c|}
\hline & & Distracted & $\begin{array}{c}\text { Interest/ } \\
\text { Enjoyment }\end{array}$ & $\begin{array}{c}\text { Affect } \\
\text { Valence }\end{array}$ & Connected & Bored & $\begin{array}{l}\text { Time } \\
\text { Slow }\end{array}$ \\
\hline \multicolumn{8}{|l|}{ Fixed Components } \\
\hline Intercept & $\hat{\gamma}_{00}$ & $2.49^{* * *}$ & $5.29^{* * *}$ & $5.67^{* * *}$ & $5.81^{* * *}$ & $2.40^{* * *}$ & $2.73^{* * *}$ \\
\hline Phone Use (Yes, No) & $\hat{\gamma}_{10}$ & $.95^{* * *}$ & $-.41^{* * *}$ & $-.31^{* * *}$ & $-.33^{* * *}$ & $.53^{* * *}$ & $.34^{* * *}$ \\
\hline \multicolumn{8}{|l|}{$\begin{array}{l}\text { Variance of Random } \\
\text { Components }\end{array}$} \\
\hline Random Intercept & $\hat{\tau}_{00}$ & $.43^{* * *}$ & $.50^{* * *}$ & $.52^{* * *}$ & $.49^{* * *}$ & $.40^{* * *}$ & $.66^{* * *}$ \\
\hline Residual & $\hat{\sigma}^{2}$ & $2.23^{* * *}$ & $1.75^{* * *}$ & $1.61^{* * *}$ & $1.46^{* * *}$ & $2.13^{* * *}$ & $2.30^{* * * *}$ \\
\hline
\end{tabular}

Note. ${ }^{* * *} \mathrm{p}<.001$. 